\title{
Loosening the Reins or Tightening Them? Complex Relationships Between Parenting, Effortful Control, and Adolescent Psychopathology
}

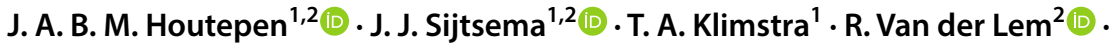 \\ S. Bogaerts ${ }^{1,2}$ (i)
}

Published online: 16 October 2018

(C) The Author(s) 2018

\begin{abstract}
Background Adolescents face major developmental tasks such as increasing individuation and establishing autonomy. These developmental tasks increase demands on adolescent self-control, hereby putting youth with poor effortful control at risk for psychopathology. Specific parenting behaviors might be warranted to buffer against this risk.

Objective This study was designed to examine parenting-related risk and protective factors in the associations between effortful control and adolescent psychopathology. We hypothesized that youth with poor effortful control require more parental involvement (i.e., lower autonomy granting) to help complete these developmental tasks and subsequently avoid psychopathology.

Methods Via adolescent self-reports $(N=809)$, associations between effortful control, perceived parenting (i.e., psychological control and autonomy support), and externalizing (i.e., interpersonal aggression and rule-breaking) and internalizing problems (i.e., depressive and anxiety problems) were examined.
\end{abstract}

Results Regression analyses supported our hypothesis in boys: higher levels of autonomy support exacerbated the negative association between effortful control and rule-breaking. In contrast, in girls this was the case for lower levels of autonomy support. For both genders, low autonomy support and psychological control exacerbated negative associations between effortful control and internalizing problems. No buffering effects of parenting were found.

Conclusions Low effortful control is associated with psychopathology in adolescents, but parenting can affect this association in several ways, depending on the type of psychopathology and the adolescent's gender. Future research should focus on finding 'optimal' levels of parental control that can help avoid psychopathological problems in youth with poor effortful control.

Keywords Effortful control · Parenting - Psychological control - Autonomy support · Adolescent psychopathology $\cdot$ Externalizing and internalizing problems

J. A. B. M. Houtepen

j.a.b.m.houtepen@uvt.nl

Extended author information available on the last page of the article 


\section{Introduction}

Effortful control reflects the ability to voluntarily inhibit, activate, or change attention and behavior in response to the environment (Rothbart 1989). It is implicated in effective emotion regulation and in adhering to socially appropriate standards (Eisenberg et al. 2011). Higher levels of effortful control in youth are typically associated with better behavioral adjustment (Gardner et al. 2008), whereas lower levels are associated with externalizing and internalizing psychopathology, including aggression, rule-breaking, and mood and anxiety problems (Eisenberg et al. 2009; Finkenauer et al. 2005; Oldehinkel et al. 2004). Psychopathology is more likely to occur in youth with poor effortful control. This risk further increases if youth also experience difficulties within their social context (Bates et al. 1998), such as problematic parenting. Previous research reported consistently that youth with low effortful control who also experience problematic parenting, are likely to show externalizing problems (e.g., Bates et al. 1998; Morris et al. 2002).

For internalizing problems, there is less research examining the contributions of interactions between effortful control and parenting, and results are mixed. Whereas some studies in children found ineffective parenting practices to be associated with more internalizing problems in children with low effortful control (Lengua et al. 2000), another study reported that the association between ineffective parenting and effortful control on internalizing problems is stronger for children with high effortful control (Van Leeuwen et al. 2004). To our knowledge, there are no studies examining these interactions in association with internalizing problems in adolescents. This is surprising, because parental influences on the development of psychopathology likely differ for children and adolescents. Adolescence is marked by biological and social changes which can lower the impact of parental influences on adolescent emotion regulation (e.g., Graham et al. 2017), and increase the need for selfcontrol to avoid developmental difficulties. These changes put adolescents with poor effortful control at risk for both externalizing and internalizing psychopathology.

In addition, previous studies mainly focused on parenting-related risk factors for psychopathology, and therefore little is known about parenting-related protective factors buffering psychopathology in youth with poor effortful control (Veenstra et al. 2006; Rutter 2001). In general, youths who are at risk for developing psychopathology are thought to be more affected by their parents' behavior, for better or worse, than youths without such risk factors (Belsky et al. 1998; Stice and Gonzales 1998). Hence, it is important to examine both parenting-related risk and protective factors for psychopathology in adolescents with poor effortful control.

In the present study, we aim to gain more insight into both risk and protective factors of externalizing and internalizing psychopathology in adolescents with poor effortful control. Associations between effortful control, parenting, and psychopathology are complex and likely depend on a number of factors, including type of psychopathology, parenting style, and gender differences in the display of psychopathology. Moreover, what may or may not be effective parenting likely depends on the developmental tasks adolescents are facing (Steinberg and Silk 2002). Earlier studies often address only a few of these issues while examining psychopathology in youth with low effortful control. This may present an oversimplified picture of risk factors for psychopathology and may lead to mixed results. In this study, we address these issues by examining interactions between effortful control and different parenting styles in their associations with externalizing and internalizing psychopathology in adolescent boys and girls. 


\section{Developmental Tasks in Adolescence and Parenting: Loosening the Reins}

During adolescence, youth face major normative developmental tasks such as increasing individuation, establishing autonomy, and seeking more independence from primary caregivers (Steinberg and Morris 2001). This individuation process requires specific parenting behaviors that permit adolescents to develop their own opinions and beliefs (Koepke and Denissen 2012; Steinberg and Silk 2002). In previous research, these parenting behaviors are often operationalized alongside parent style dimensions (Soenens et al. 2004), of which parental autonomy support and psychological control are particularly important during adolescence.

Autonomy support refers to parents' promotion of children's independence- and volitional functioning (Soenens et al. 2007), and the degree to which parents let their children make independent decisions (Beyers and Goossens 1999). Control by parents who provide autonomy support is thought to closely resemble executing behavioral control (Hauser-Kunz and Grych 2013), such as discouraging independency by setting clear rules for children's behavior. In contrast, psychological control reflects intrusive and manipulative parental behavior, such as inducing feelings of guilt and shame in order to control children's behavior (Soenens et al. 2004). Both parenting styles are directly related to the extent to which parents assist children in fulfilling adolescent developmental tasks of gaining independency and autonomy. Higher levels of parental autonomy support are associated with positive psychosocial outcomes, such as feelings of social competence (Soenens and Vansteenkiste 2005). In contrast, higher levels of psychological control may interfere with normative developmental tasks of mastering independence and emotional autonomy (Reitz et al. 2006), and have been associated with both externalizing and internalizing problems (e.g., Lansford et al. 2014; Pettit et al. 2001).

Furthermore, lower levels of psychological control combined with higher levels of autonomy support reflect psychological autonomy granting (Steinberg 2001). Psychological autonomy granting is the degree to which parents encourage and permit adolescents to develop their own opinions and beliefs. Higher levels of psychological autonomy granting are thought to be associated with better psychosocial functioning in adolescents (Steinberg 2001). In this respect, psychological autonomy granting is considered a general protective factor against adolescent psychopathology. Moreover, because psychological autonomy granting can enhance feelings of self-worth and competence in adolescents, it is also thought to protect against internalizing problems (Gray and Steinberg 1999).

\section{Adolescents with Poor Effortful Control: Tightening the Reins?}

However, what is considered effective parenting for one adolescent is not necessarily effective for another (e.g., Belsky 1997). Although psychological autonomy granting is generally associated with better psychosocial functioning in adolescence (Steinberg 2001), higher levels of autonomy are also associated with adolescent psychopathology in some studies. For example, adolescent emotional autonomy (i.e., provided to adolescents through low levels of parental psychological control) was positively associated with internalizing problems, and behavioral autonomy (i.e., provided through higher 
levels of parental autonomy support) was associated with more rule-breaking behavior (Beyers and Goossens 1999).

In part, these contrasting findings on autonomy and adolescent functioning may be explained by considering to what extent autonomy is mastered by a sense of volition instead of forced upon the adolescent through parenting (Van Petegem et al. 2013). Yet, the extent to which psychological autonomy granting is beneficial to an adolescent also depends on whether adolescents are ready to successfully establish independency and autonomy, and the degree to which they are able to control their own behavior. For example, studies suggest that providing adolescents with behavioral autonomy when they are not yet ready, is associated with both externalizing and internalizing problems (Dishion et al. 2004; Pavlova et al. 2011). This is more likely to be a problem for adolescents with poor effortful control, because for them it is more difficult to successfully complete developmental tasks. Specifically, the increased responsibility, independence, and freedom that is experienced during adolescence, places higher demands on adolescent self-control, which put adolescents with poor effortful control at an increased risk for psychopathology (Pérez-Edgar 2015).

Therefore, it could be argued that for adolescents with low effortful control, the level of autonomy support that is needed to actively assist them in completing normative developmental tasks and subsequently avoid psychopathology is lower. Similarly, previous research on children indicated that for some children with poor self-regulation, higher levels of restrictive parental control (i.e., lower levels of psychological autonomy) are needed to diminish externalizing problems (Bates et al. 1998; Kiff et al. 2011). Hence, we expect lower levels of parental autonomy support, but not necessarily higher levels of psychological control, to be associated with better psychosocial outcomes in adolescents with poor effortful control. Parents who use psychological control employ manipulative tactics in order to make their children act or think according to their standards (Barber and Harmon 2002). Such parenting is less sensitive to the needs and interests of children (Soenens et al. 2007), and therefore is considered as a general risk factor for psychopathology, regardless of children's level of effortful control.

\section{The Current Study}

In sum, despite a wealth of studies focusing on interactions between effortful control and parenting in relation to psychopathology in youth, there is a lack of knowledge regarding internalizing problems and protective factors for psychopathology in general. A major challenge lies in determining what is considered effective parenting for youth with poor effortful control in relation to psychopathological problems, as this may depend on the specific developmental tasks that are being faced (Steinberg 2001; Steinberg and Silk 2002). Finally, the interaction between effortful control and parenting in relation to adolescent psychopathology may also depend on the gender of the adolescent. As noted earlier, studies indicated that youth who are more at risk for psychopathology are more affected by their parents' behaviors (Belsky et al. 1998; Stice and Gonzales 1998). Parenting may thus have a stronger impact on boys' externalizing problems because boys are at more risk for developing these compared to girls (see also Veenstra et al. 2006). Similarly, for girls this may be the case for internalizing problems (see for example Graham and Weems 2015).

In the present study, interactions between effortful control and parenting are examined in relation to adolescents' externalizing (i.e., interpersonal aggression and rule-breaking) and internalizing problems (i.e., depressive and anxiety problems). Although gaining 
behavioral and emotional autonomy is part of normative development, previous work showed that both are associated with internalizing and externalizing psychopathology in some adolescents (e.g., Dishion et al. 2004; Pavlova et al. 2011). Moreover, research indicates that children with poorer self-regulatory abilities sometimes need more parental involvement in order to lower psychopathological problems (e.g. Kiff et al. 2011). Based on these findings, we argue that youth with poor effortful control need more parental control in order to successfully cope with developmental tasks and avoid psychopathology. Hence, we hypothesize that negative associations between effortful control and externalizing and internalizing psychopathology are stronger in adolescents who perceive more parental psychological control and autonomy support (i.e., more psychological autonomy granting) (hypothesis 1). Moreover, we expect that lower levels of perceived psychological control and autonomy support (i.e., less psychological autonomy granting) mitigate the negative associations between effortful control and psychopathological problems (hypothesis 2). Finally, we hypothesize that the interaction between effortful control and parenting in relation to externalizing problems will be more pronounced for boys compared to girls, whereas we expect the inverse pattern (i.e., a stronger interaction effect between effortful control and parenting for girls) in relation to internalizing problems (hypothesis 3).

\section{Method}

\section{Participants}

Participants were 866 subjects ( $M$ age $=13.84$ years, $S D=1.06$, range 11-16) of the Study on Personality, Adjustment, Cognition, and Emotion II (SPACE II). SPACE II is a Dutch cohort study focusing on the psychosocial development of adolescents from the general population. Participants were recruited via four secondary schools, located in four medium- to large-sized cities in the Netherlands. In the Netherlands, secondary schools are often divided into low to moderate education levels (i.e., combinations of vocational training and theoretical education), and higher educational levels (i.e., preparatory tracks for professional education or university). In this study, almost all participants were enrolled in the higher education levels (93.3\%). More than half of the sample was of Dutch nationality $(64.5 \%)$. Other nationalities included Turkish (7.7\%), Moroccan (6.6\%), and Surinamese $(5.3 \%)$.

\section{Procedure}

SPACE II was conducted in accordance with the Code of Ethics of the World Medical Association (Declaration of Helsinki) and approved by the local Institutional Review Board at the host university of the first author. Before initiating the study, school principals were asked for permission to collect data at their schools. Next, parents were notified about the nature of the study by information letters in which the purpose and procedure of the study was described. SPACE II uses a passive informed consent procedure for parents, which is common in the Netherlands. Details about the study were explained in the information letter, and parents were given the opportunity to object to their children's participation within 2 weeks after receipt of the information letter. Finally, adolescents were informed about the nature of the study and were asked whether they wanted to participate. Participants were able to withdraw from the study at any time, without having to provide a reason for this. 
In 2014, data collection took place during school hours, under the supervision of trained bachelor's and master's of psychology students.

\section{Measures}

\section{Effortful Control}

Effortful control was measured using 16 items $(\alpha=.77)$ of the Early Adolescent Temperament Questionnaire-Revised (EATQ-R; Ellis and Rothbart 2001). The EATQ-R contains various subscales assessing three main factors of children's temperament, including effortful control. Participants completed the questionnaire by indicating on a 5-point Likert-scale (i.e., $1=$ almost never true to $5=$ almost always true), how much they agreed with statements, such as: "If I have a hard assignment to do, I get started right away". Mean total effortful control scores were computed by averaging participants' scores on the 16 items. Previous studies have found support for the internal consistency and validity of the EATQR (Muris and Meesters 2009).

\section{Parenting}

Parental psychological control and autonomy support as perceived by the adolescent were measured using the Leuven Adolescent Perceived Parenting Scale (LAPPS; Soenens et al. 2004). In this study, the subscale psychological control was assessed for mothers and fathers, separately (e.g., "My mother/father will avoid looking at me when I have disappointed her/him"). We averaged mother- and father-ratings in order to create one parental psychological control score for both parents (16 items; $\alpha=.90)$. Autonomy support was assessed for both parents together (e.g., "My parents let me choose my own direction, whenever that is possible") (5 items; $\alpha=.78)$. Adolescents indicated on a 5-point Likert scale ranging from 1 (completely disagree) to 5 (Completely agree) how much they agreed with the items. Higher mean total scores indicate higher adolescent perceived levels of that particular parenting style. The internal consistency and construct validity of the LAPPS have been supported in previous research (e.g., Soenens et al. 2004; Beyers and Goossens 2008).

\section{Externalizing Psychopathology}

Interpersonal aggression and rule-breaking behavior were measured using 27-items of the Antisocial Behavior Questionnaire (ASBQ), which is based on the Self-report Delinquency Scale (Moffitt and Silva 1988). The ASBQ consists of items that measure both engagement in interpersonal aggression (e.g., "How often did you engage in a physical fight?"; 10 items, $\alpha=.79$ ), and engagement in rule-breaking behavior in the past 12 months (e.g., "How often have you stolen something from a store?"; 17 items, $\alpha=.88$ ). Responses were rated on a 5 -point scale as $0=$ never, $1=$ once, $2=$ two or three times, $3=$ four to six times, and $4=$ seven times or more. Higher mean total scores indicate more use of interpersonal aggression and rule-breaking behavior. Previous research has shown that the ASBQ is a reliable instrument in terms of internal consistency and construct validity (Van der Laan et al. 2010). 


\section{Internalizing Psychopathology}

Depressive problems were measured with the 12 item $(\alpha=.83)$ version of the Center for Epidemiologic Studies Depression Scale (CES-D-12-NLSCY; Radloff 1977; Poulin et al. 2005). The CES-D is designed to assess current levels of depressive symptoms in the general population. Respondents indicated on a 4-point scale $[1=$ rarely or none of the time (less than 1 day), $2=$ some or a little of the time (1-2 days), $3=$ occasionally or a moderate amount of time (3-4 days), 4= most or all of the time (5-7 days)] how often in the past week they experienced symptoms, such as "I had crying spells". Higher total mean scores indicate more depressive problems. The CES-D tends to have good internal consistency and construct validity (Radloff 1977).

Anxiety problems were assessed using the generalized anxiety disorder subscale (5 items; $\alpha=.84$ ) of the Screen for Child Anxiety Related Emotional Disorders-Revised (SCARED-R; Muris et al. 1999). Adolescents were asked to rate how often they had experienced each symptom (e.g., "I worry about being as good as other kids") on a 3-point scale $(0=$ almost never, $1=$ sometimes, $2=$ often $)$. Higher scores are indicative of more generalized anxiety problems, and more generalized worrying and rumination, specifically. The SCARED-R was found to be a reliable and valid instrument in previous research (Muris et al. 1998, 1999).

\section{Statistical Analysis}

Descriptive analyses of all study variables were conducted to examine score distributions and missing values. In the original sample, $6.2 \%$ of the participants had missing data on more than half of the items on the questionnaires measuring the dependent or independent variables (i.e., 54 participants of originally 866 participants in total). These participants were excluded from further analyses. In addition, 3 participants had not filled out their gender. For the remaining 809 participants, Little's (1988) Missing Completely At Random test indicated that their values were missing at random. Therefore, we replaced these missing values by single imputation using the Expectation Maximization algorithm. This is an efficient way of handling missing data when it is missing at random or completely at random (Dong and Peng 2013).

We examined gender differences using independent sample $t$-tests and estimated effect sizes using Cohen's $d$. Associations between study variables were examined using Pearson correlations. Thereafter, we conducted multiple hierarchical regression analyses in order to examine the associations between effortful control, perceived parenting, and externalizing and internalizing psychopathology. In all analyses, the first step included main effects of gender, age, school, effortful control, and parenting. In step two, we added two-way interactions between effortful control and parenting. Finally, in step three, three-way interactions were included in order to test whether the associations between effortful control, parenting, and psychopathology differed between boys and girls. To reduce problems with multicollinearity, all continuous independent variables were mean centered (Kraemer and Blasey 2004). Estimates of effect sizes were estimated by calculating the squared semi-partial correlations $\left(s r^{2}\right)$ for significant effects (e.g., Fritz et al. 2012). When significant interaction effects were found, simple slopes were calculated using the Process macro for SPSS (Hayes 2013). This allowed us to test whether effortful control affected psychopathology at different levels of parenting. In addition, Johnson and Neyman's (1936) significance regions 
were calculated to determine the range of values of the moderator for which there was a significant association between effortful control and psychopathology.

\section{Results}

\section{Descriptive Analyses}

Descriptive statistics and correlations between all study variables are reported in Table 1. Independent sample $t$-tests showed that boys reported more externalizing problems (i.e., Cohen's $d$ for interpersonal aggression $=0.44$, for rule-breaking behavior $d=0.17$ ), whereas girls reported more internalizing problems (i.e., Cohen's $d$ for depressive $=0.30$, and for anxiety problems $d=0.37$ ). Interpersonal aggression and rule-breaking behavior were not normally distributed. Therefore, we calculated correlations involving these variables by using Spearman's rho instead of Pearson's correlations (e.g., Field 2009). Generally, effortful control was negatively associated with both externalizing and internalizing psychopathology. In addition, parental psychological control was positively associated with more externalizing and internalizing psychopathology. Autonomy support was negatively associated with internalizing psychopathology, but unrelated to externalizing psychopathology.

\section{Effortful Control, Parenting, and Externalizing and Internalizing Psychopathology}

Table 2 shows results of the hierarchical regression analyses of interpersonal aggression, rule-breaking behavior, depressive problems, and anxiety problems. Because we were mainly interested in the interaction effects between effortful control and perceived parenting, we limited our discussion to the interaction effects, but reported all effects in Table 2. Of note, to test the hypotheses for externalizing problems, dependent variables were log transformed, and we performed bootstrapping because interpersonal aggression and rulebreaking behavior were not normally distributed (Russel and Dean 2000). Furthermore, the assumption of homoscedasticity was violated in the regression analyses including interpersonal aggression, rule-breaking behavior, and anxiety problems. Therefore, we tested whether heteroscedasticity led to invalid hypothesis testing in these models, by using heteroscedasticity-consistent standard error (HCSE) estimators in Ordinary Least Square regression (version HC3, Hayes and Cai 2007).

\section{Interpersonal Aggression}

Two-way interactions between effortful control and perceived parenting, and three-way interactions that additionally included gender, did not significantly predict interpersonal aggression (see Table 2). Main effects indicated that younger age $\left(s r^{2}<.01\right)$, lower effortful control $\left(s r^{2}=.04\right)$, and more parental psychological control $\left(s r^{2}=.01\right)$ were associated with more interpersonal aggression. In addition, boys displayed more interpersonal aggression than girls $\left(s r^{2}=.06\right)$.

\section{Rule-Breaking Behavior}

With regard to rule-breaking behavior, there was a significant three-way interaction between effortful control, autonomy support, and gender $\left(s r^{2}=.01\right)$. We calculated 


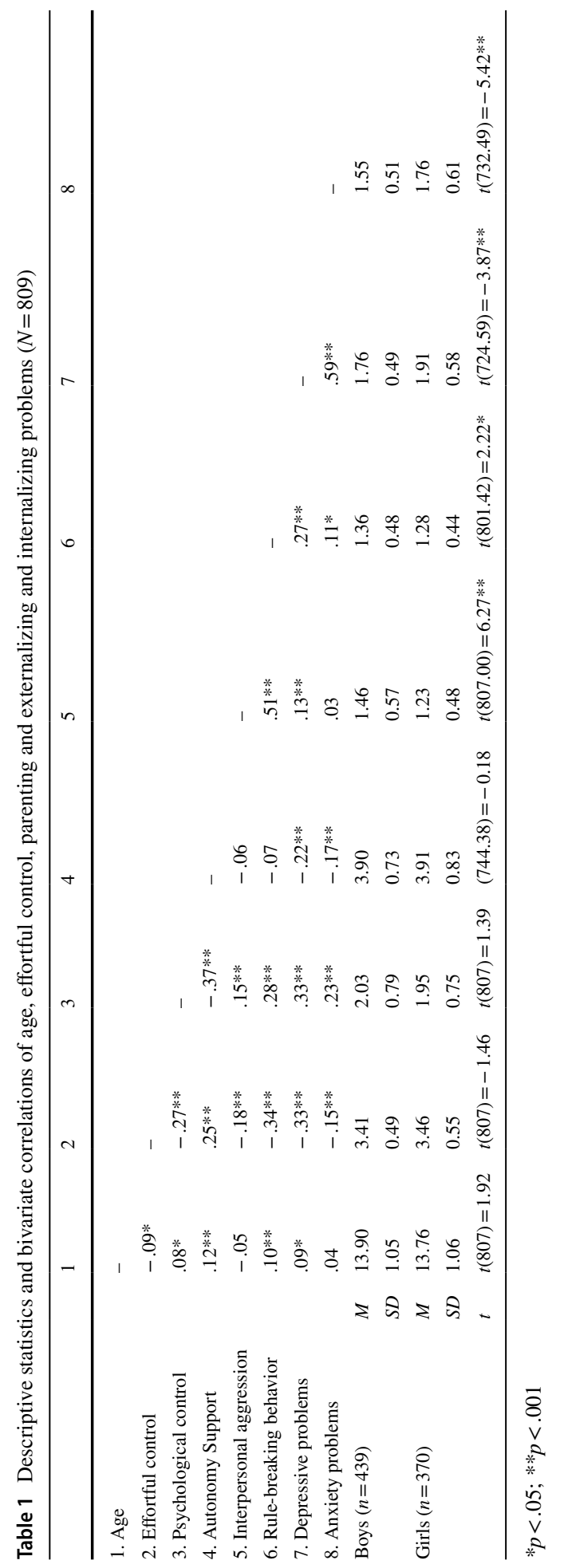




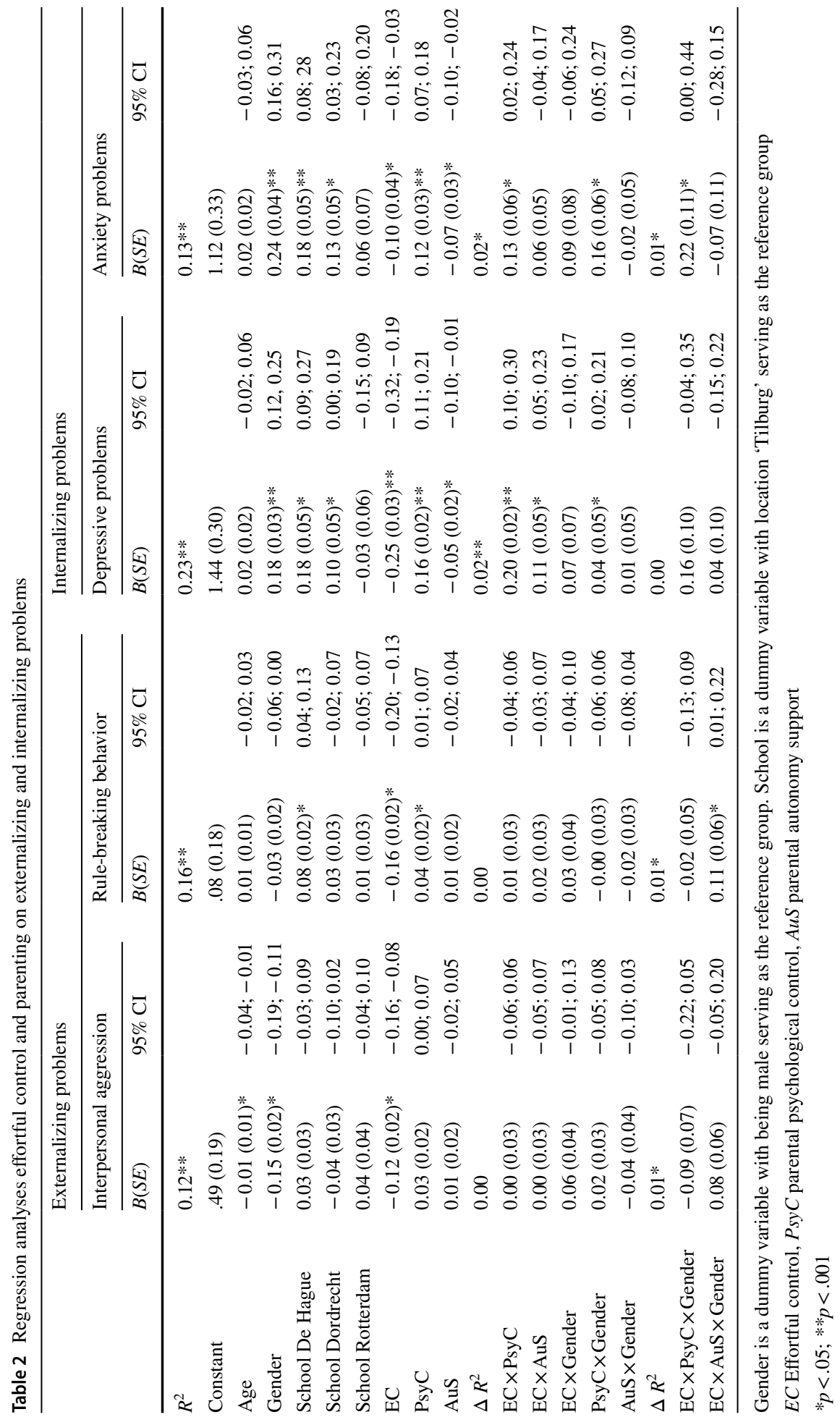


simple slopes for effortful control at low (1 SD below the mean), and high (1 SD above the mean) levels of autonomy support. For both genders, there was a significant negative association between effortful control and rule-breaking behavior at all levels of autonomy support, such that lower levels of effortful control were associated with more rule breaking (see Fig. 1a). As hypothesized, for boys the association between effortful control and rule-breaking behavior was stronger at high levels of autonomy support $\left(b_{\text {boys }}\right.$ slope low $=-0.12, S E=0.05$, CI 95\% $[-0.23 ;-0.02] ; b_{\text {boys }}$ slope high $=-0.20$, $S E=0.05$, CI 95\% [-0.29; -0.12$])$. In contrast, for girls the association between
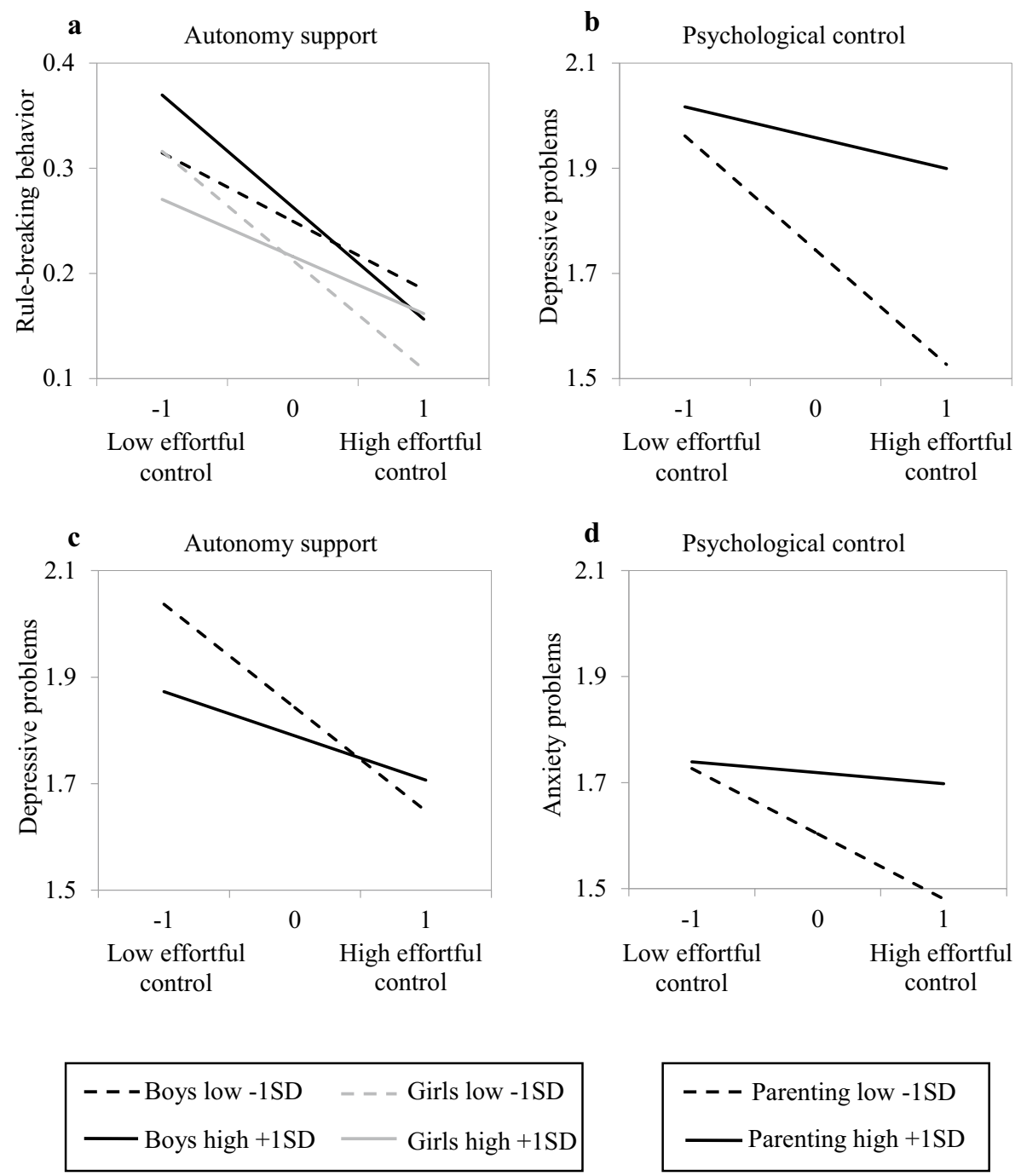

- - - Parenting low -1SD

Parenting high +1 SD

Fig. 1 Two- and three-way interactions effortful control and parenting on externalizing and internalizing problems 
effortful control and rule breaking was stronger for those who perceived low levels of autonomy support (i.e., $b_{\text {girls }}$ slope low $=-0.20, S E=0.03$, CI 95\% [-0.27; -0.13$]$; $b_{\text {girls }}$ slope high $=-0.10, S E=0.03$, CI 95\% $\left.[-0.16 ;-0.05]\right)$.

\section{Depressive Problems}

Two-way interactions between effortful control and psychological control $\left(s r^{2}=.02\right)$ and between effortful control and autonomy support $\left(s r^{2}=.01\right)$ were significantly associated with internalizing psychopathology. In contrast to the first hypothesis, a simple slope analysis showed that at low levels of parental psychological control ( $b$ slope low $=-0.42, S E=0.06$, CI 95\% [-0.53; -0.31$]$ ), lower effortful control was associated with more depressive problems (Fig. 1b). At high levels of psychological control (i.e., scores of .71 above the mean of 0 , and higher), there was no association between effortful control and depressive problems. For autonomy support, a significant negative association was found between effortful control and depressive problems, at low and high levels of support (Fig. 1c). In contrast to the first two hypotheses, this association was stronger when levels of autonomy support decreased (i.e., $b$ slope low $=-0.37$, $S E=0.06$, CI 95\% [-0.50; -0.25$] ; b$ slope high $=-0.16, S E=0.05$, CI 95\% [ -0.27 ; $-0.05])$. Furthermore, regions of significance showed that only at extremely high levels of autonomy support (i.e., scores of 1.05 above the mean and higher), there was no association between effortful control and depressive problems.

Finally, in contrast to hypothesis 3, there were no significant three-way interactions between gender, effortful control, and perceived parenting in predicting depressive problems. However, a significant interaction effect between gender and psychological control $\left(s r^{2}=.01\right)$ indicated that the positive association between parental psychological control and depressive problems was stronger for girls than for boys (i.e., $b_{\text {girls }}$ slope $=0.25$, $S E=0.05$, CI 95\% [0.16;0.34]; $b_{\text {boys }}$ slope $=0.14, S E=0.03$, CI 95\% $\left.[0.08 ; 0.20]\right)$.

\section{Anxiety Problems}

Two-way interactions showed that the negative association between effortful control and anxiety problems depended on the level of parental psychological control $\left(s r^{2}=.01\right)$. Similar to the results on depressive problems, there was only a significant negative association between effortful control and anxiety at lower and intermediate levels of parental psychological control (i.e., $b$ slope low $=-0.24, S E=0.07$, CI 95\% $[-0.36 ;-0.11]$ ). At psychological control scores of .18 above the mean or higher, the association between effortful control and anxiety problems was not significant (Fig. 1d). The regression analysis suggested that this interaction differed between boys and girls $\left(s r^{2}<.01\right)$, but when tested with the HCSE estimator, this association was no longer significant (i.e., $b=0.22$, $S E(H C)=0.12$, CI 95\% [-0.01;0.45]). Hence, our gender hypothesis was not supported by the data. There was a positive interaction between psychological control and gender $\left(s r^{2}=.01\right)$, suggesting that for girls the positive association between parental psychological control and anxiety problems was stronger than for boys (i.e., $b_{\text {girls }}$ slope $=0.24$, $S E=0.05$, CI 95\% $[0.14 ; 0.33] ; b_{\text {boys }}$ slope $=0.07, S E=0.04$, CI 95\% $\left.[0.01 ; 0.14]\right)$. 


\section{Discussion}

In this study, we examined interactions between effortful control and perceived parenting in relation to externalizing and internalizing problems in adolescents. Because normative developmental tasks in adolescence place high demands on self-control, we hypothesized that youth with low effortful control may require more parental involvement (i.e., lower autonomy granting) to cope with these developmental tasks and subsequently avoid psychopathology. Our results supported this hypothesis in boys: higher levels of autonomy support exacerbated the negative association between effortful control and rule breaking. In contrast, in girls this was the case for lower levels of autonomy support. In both genders, lower levels of autonomy support were associated with depressive problems in adolescents with low effortful control. Our second hypothesis was not supported, as lower levels of psychological control and autonomy support did not mitigate negative associations between effortful control and adolescents' psychopathology. Moreover, although parenting was related to psychopathology in adolescents with low levels of effortful control, the predominant pattern of findings was that these adolescents reported more psychopathology, regardless of perceived parenting, gender, and type of psychopathology.

The finding that lower levels of parental involvement exacerbated rule-breaking behavior in boys with poor effortful control suggests that these boys have difficulties in regulating their behavior, and thus require external sources of control. In line with this, Bates et al. (1998) showed that higher levels of maternal control could be a protective factor against externalizing problems in children with poor self-regulatory capacities. Furthermore, our results align with previous research showing that behavioral autonomy is associated with rule breaking in adolescence (Beyers and Goossens 1999).

For girls with low levels of effortful control, this association was different: lower levels of autonomy support were more strongly related to rule-breaking. A possible explanation for this gender difference is that because boys are at higher risk for rule-breaking behavior than girls (e.g., Crick and Zahn-Waxler 2003), they need more stringent rules (Lengua 2008). Furthermore, in early and mid-adolescence, biological maturation differs between boys and girls (Beyers and Goossens 1999), as girls are approximately 2 years ahead in their biological development (Tanner et al. 1966). Importantly, this biological development likely precedes the development of autonomy striving in adolescence (Steinberg 1987) and is associated with psychological processes such as personality development (Klimstra et al. 2009). Because we studied young adolescents, it is possible that higher levels of parental autonomy support fit better with low-effortful-control girls' developmental stage than that of boys, such that lower levels of autonomy were associated with more rule breaking. This also implies that our results regarding the associations between effortful control and rulebreaking behavior in boys who perceived high autonomy support in part reflect the boys' immaturity in establishing autonomy and individuation (see also Dishion et al. 2004). Hence, both premature behavioral autonomy and poor effortful control can be risk factors for rule-breaking behavior in young adolescents.

Furthermore, different parenting-related risk factors were associated with externalizing and internalizing psychopathology in adolescents with low effortful control. For both genders, lower levels of autonomy support were more strongly related to depressive problems in youth with low levels of effortful control. Corroborating this with the findings on rulebreaking behavior, this suggests that for boys with low levels of effortful control, both high and low levels of autonomy support are associated with psychopathology. Although perceiving low levels of autonomy support can mitigate rule-breaking behavior in boys with 
low effortful control, it may also lead to feelings of being restricted, which in turn may be associated with depressive problems. Therefore, it seems that parents of boys with low levels of effortful control should strive for a balance between low and high levels of autonomy support in order to protect their boys against psychopathology (see also Sentse et al. 2010). In contrast, for girls, findings are similar for depressive problems and rule-breaking behavior and resonate with earlier research, which indicated that higher levels of psychological autonomy are associated with better adolescent functioning in general and with lower levels of internalizing problems in particular (Gray and Steinberg 1999).

We found no support for our second hypothesis, but instead found that particularly lower levels of psychological control strengthened negative associations between effortful control and internalizing problems. These findings are in contrast with earlier research on parental psychological control. Yet, Beyers and Goossens (1999) already reported that emotional autonomy, provided through low levels of psychological control, is associated with internalizing problems in adolescence. We extended these findings by showing that emotional autonomy is more strongly related to psychopathology in adolescents with low effortful control. Furthermore, reported psychopathology among adolescents with low effortful control did not appear to depend on the levels of parental psychological control they perceived. Both low and high levels of psychological control thus seem risk factors for psychopathology in adolescents with low levels of effortful control. In line with findings on autonomy support for boys, this suggests that parents of adolescents with low effortful control should also strive for optimally balanced, rather than low or high, levels of control to lower risk for psychopathology (Lengua 2008; Sentse et al. 2010).

Finally, we found no support for our gender hypothesis. However, we found that for girls in general, perceived psychological control was more strongly related to internalizing problems. To date, results on gender differences in the association between psychological control and adolescent psychopathology have been inconsistent, and findings often indicate that influences of psychological control are universal across gender (e.g., Cui et al. 2014). However, our finding resonates with the more general vulnerability hypothesis, which states that compared to boys, girls' internalizing problems are more influenced by parenting because they are at higher risk to develop internalizing problems.

Some limitations need to be mentioned. First, most of the reported associations of effortful control and parenting with externalizing and internalizing psychopathology had small effect sizes, and thus should be interpreted with caution. Second, our data were solely based on self-reports. It is likely that reports on perceived parenting were colored by other factors, such as the quality of the parent-child relationship. Nevertheless, adolescents' perceptions of parenting are highly important in studying associations with their behavior, because adolescents' mental representations of their parents' behavior will likely matter more than the parents' actual behavior (Main et al. 1985). Third, our sample mainly included adolescents who were enrolled in the higher educational tracks of secondary school. Academic success is associated with higher levels of effortful control (Valiente et al. 2008). Therefore, adolescents with poor effortful control may have been underrepresented in this study. Fourth, because our results were based on cross-sectional data, parenting styles may have been reflections of parents' reactions to symptoms of adolescent psychopathology. Previous research suggests that parental involvement can be reduced as a reaction to being confronted with adolescent problem behavior (Dishion et al. 2004). This may explain our findings regarding rule-breaking behavior and high autonomy support in boys with low effortful control. Finally, we did not examine interactions between parenting styles, which may have affected our results on psychological control. It has been suggested that the consequences of emotional autonomy may differ depending on the quality of the 
child-parent relationship (Lamborn and Steinberg 1993), such that emotional autonomy is associated with good psychosocial adjustment when adolescents also perceive high parental support. Future research could examine this hypothesis, because to our knowledge, these parenting style interactions have not been examined in adolescents with low effortful control yet.

In sum, we showed that low effortful control is associated with psychopathology. Parenting affected this association in several ways, depending on the type of psychopathology and the adolescent's gender. Based on the current study it is not clear whether more psychological autonomy granting of parents can buffer against psychopathology in youth with low levels of effortful control. Yet, for adolescents with poor effortful control, perceived autonomy support can affect the level of externalizing and internalizing psychopathology to some extent, with different effects for boys and girls. For girls with poor effortful control, particularly lower levels of autonomy were associated with psychopathology, whereas for boys with low effortful control, higher levels of perceived autonomy increased the display of rule-breaking behavior. Caution is warranted as these results were based on crosssectional data and represented small effect sizes. Our conclusions are thus tentative and require replication, preferably in a longitudinal design that can test the directionality of effects. Nevertheless, these results suggest that especially for boys with poor effortful control, future research should aim to find what optimal levels of parental support and control are, for whom, and under what circumstances, in order to find out to what extent parents can loosen the reins, while still keeping a safe grip.

\section{Compliance with Ethical Standards}

Conflict of interest The authors declare that they have no conflict of interest.

Research Involving Human Participants All procedures performed in this study involving human participants were in accordance with the ethical standards of the institutional research committee, and with the 1964 Helsinki declaration and its later amendments or comparable ethical standards.

Informed consent Informed consent was obtained from all individual participants included in the study.

Open Access This article is distributed under the terms of the Creative Commons Attribution 4.0 International License (http://creativecommons.org/licenses/by/4.0/), which permits unrestricted use, distribution, and reproduction in any medium, provided you give appropriate credit to the original author(s) and the source, provide a link to the Creative Commons license, and indicate if changes were made.

\section{References}

Barber, B. K., \& Harmon, E. L. (2002). Violating the self: Parental psychological control of children and adolescents. In B. K. Barber (Ed.), Intrusive parenting: How psychological control affects children and adolescents (pp. 15-52). Washington, DC: American Psychological Association.

Bates, J. E., Pettit, G. S., Dodge, K. E., \& Ridge, B. (1998). Interaction of temperamental resistance to control and restrictive parenting in the development of externalizing behavior. Developmental Psychology, 34, 985. https://doi.org/10.1037/0012-1649.34.5.982.

Belsky, J. (1997). Variation in susceptibility to environmental influences: An evolutionary argument. Psychological Inquiry, 8(3), 182-186.

Belsky, J., Hsieh, K. H., \& Crnic, K. (1998). Mothering, fathering, and infant negativity as antecedents of boys' externalizing problems and inhibition at age 3 year: Differential susceptibility to rearing experience? Development and Psychopathology, 10, 301-319. https://doi.org/10.1017/S095457949800162X. 
Beyers, W., \& Goossens, L. (1999). Emotional autonomy, psychosocial adjustment and parenting: Interactions, moderating and mediating effects. Journal of Adolescence, 22, 753-769. https://doi.org/10.1006/ jado.1999.0268.

Beyers, W., \& Goossens, L. (2008). Dynamics of perceived parenting and identity formation in late adolescence. Journal of Adolescence, 31, 165-184. https://doi.org/10.1016/j.adolescence.2007.04.003.

Crick, N. R., \& Zahn-Waxler, C. (2003). The development of psychopathology in females and males: Current progress and future challenges. Development and Psychopathology, 15, 719-742. https://doi. org/10.1017/S095457940300035X.

Cui, L., Morris, A. S., Criss, M. M., Houltberg, B. J., \& Silk, J. S. (2014). Parental psychological control and adolescent adjustment: The role of adolescent emotion regulation. Parenting, Science and Practice, 14, 47-67. https://doi.org/10.1080/15295192.2014.880018.

Dishion, T. J., Nelson, S. E., \& Bullock, B. M. (2004). Premature adolescent autonomy: Parent disengagement and deviant peer process in the amplification of problem behavior. Journal of Adolescence, 27 , 515-530. https://doi.org/10.1016/j.adolescence.2004.06.005.

Dong, Y., \& Peng, C. J. (2013). Principled missing data methods for researchers. SpringerPlus, 2, 222. https ://doi.org/10.1186/2193-1801-2-22.

Eisenberg, N., Smith, C. L., \& Spinrad, T. L. (2011). Effortful control: Relations with emotion regulation, adjustment, and socialization in childhood. In K. D. Vohs \& R. J. Baumeister (Eds.), Handbook of selfregulation (pp. 263-283). New York: Guildford Press.

Eisenberg, N., Valiente, C., Spinrad, T. L., Cumberland, A., Liew, J., Mark, R., et al. (2009). Longitudinal relations of children's effortful control, impulsivity, and negative emotionality to their externalizing, internalizing, and co-occurring behavior problems. Developmental Psychology, 45, 988. https://doi. org/10.1037/a0016213.

Ellis, L. K., \& Rothbart, M. K. (2001). Revision of the early adolescent temperament questionnaire. In Poster presented at the 2001 Biennial Meeting of the Society for Research in Child Development, Minneapolis, Minnesota.

Field, A. (2009). Discovering statistics using SPSS. London: Sage.

Finkenauer, C., Engels, R. C. M. E., \& Baumeister, R. F. (2005). Parenting behavior and adolescent behavioral and emotional problems: The role of self-control. International Journal of Behavioral Development, 29, 58-69. https://doi.org/10.1080/01650250444000333.

Fritz, C. O., Morris, P. E., \& Richler, J. J. (2012). Effect size estimates: Current use, calculations and interpretation. Journal of Experimental Psychology: General, 141, 2. https://doi.org/10.1037/a0024338.

Gardner, T. W., Dision, T. J., \& Conell, A. M. (2008). Adolescent self-regulation as resilience: Resistance to antisocial behavior within the deviant peer context. Journal of Abnormal Child Psychology, 36, 273-284. https://doi.org/10.1007/s10802-007-9176-6.

Graham, R. G., Scott, B. G., \& Weems, C. F. (2017). Parenting behaviors, parent heart rate variability, and their associations with adolescent heart rate variability. Journal of Youth and Adolescence, 46, 10891103. https://doi.org/10.1007/s10964-016-0616-x.

Graham, R. G., \& Weems, C. F. (2015). Identifying moderators of the link between parent and child anxiety sensitivity: The roles of gender positive parenting and corporal punishment. Journal of Abnormal Child Psychology, 43, 885-893. https://doi.org/10.1007/s10802-014-9945-y.

Gray, M. R., \& Steinberg, L. (1999). Unpacking authoritative parenting: Reassessing a multidimensional construct. Journal of Marriage and Family, 61(3), 547-587.

Hauser-Kunz, J., \& Grych, J. H. (2013). Parental psychological control and autonomy granting: Distinctions and associations with child and family functioning. Parenting, 13, 77-94. https://doi. org/10.1080/15295192.2012.709147.

Hayes, A. F. (2013). Introduction to mediation, moderation, and conditional process analysis: A regressionbased approach. New York: The Guilford Press.

Hayes, A. F., \& Cai, L. (2007). Using heteroscedasticity-consisted standard error estimators in OLS regression: An introduction and software implementation. Behavior Research Methods, 39, 709-722. https:// doi.org/10.3758/bf03192961.

Johnson, P. O., \& Neyman, J. (1936). Tests of certain linear hypotheses and their applications to some educational problems. Statistical Research Memoirs, 1, 47-93.

Kiff, C. J., Lengua, L. J., \& Zalewski, M. (2011). Nature and nurturing: Parenting in the context of child temperament. Clinical Child and Family Psychology Review, 14, 251. https://doi.org/10.1007/s1056 7-011-0093-4.

Klimstra, T. A., Hale, W. W., Raaijmakers, Q. A. W., Branje, S. J. T., \& Meeus, W. H. J. (2009). Maturation of personality in adolescence. Journal of Personality and Social Psychology, 96, 898. https://doi. org/10.1037/a0014746. 
Koepke, S., \& Denissen, J. J. A. (2012). Dynamics of identity development and separation-individuation in parent-child relationships during adolescence and emerging adulthood: A conceptual integration. Developmental Review, 32, 67-88. https://doi.org/10.1016/j.dr.2012.01.001.

Kraemer, H. C., \& Blasey, C. M. (2004). Centring in regression analyses: A strategy to prevent errors in statistical inference. International Journal of Methods in Psychiatric Research, 13(3), 141-151.

Lamborn, S. D., \& Steinberg, L. (1993). Emotional autonomy redux: Revisiting Ryan and Lynch. Child Development, 64, 483-499. https://doi.org/10.1111/j.1467-8624.1993.tb02923.x.

Lansford, J. E., Laird, R. D., Pettit, G. S., Bates, J. E., \& Dodge, K. A. (2014). Mothers' and fathers' autonomy-relevant parenting: Longitudinal links with adolescents' externalizing and internalizing behavior. Journal of Youth and Adolescence, 43, 1877-1889. https://doi.org/10.1007/s1096 4-013-0079-2.

Lengua, L. J. (2008). Anxiousness, frustration, and effortful control as moderators of the relation between parenting and adjustment in middle-childhood. Social Development, 17, 554-577. https:// doi.org/10.1111/j.1467-9507.2007.00438.x.

Lengua, L. J., Wolchik, S. A., Sandler, I. N., \& West, S. G. (2000). The additive and interactive effects of parenting and temperament in predicting adjustment problems of children of divorce. Journal of Clinical Child Psychology, 29, 232-244. https://doi.org/10.1207/S15374424jccp2902_9.

Little, R. J. A. (1988). A test of missing completely at random for multivariate data with missing values. Journal of the American Statistical Association, 83(404), 1198-1202.

Main, M., Kaplan, N., \& Cassidy, J. (1985). Security in infancy, childhood, and adulthood: A move to the level of representation. In: I. Bretherton \& E. Waters (eds) Growing points in attachment: Theory and research. Monographs of the society for research in child development (Vol. 50, no 1-2, pp. 66-104). Chicago: University of Chicago Press.

Moffitt, T. E., \& Silva, P. A. (1988). Self-reported delinquency: Results from an instrument for New Zealand. Australian and New Zealand Journal of Criminology. https://doi.org/10.1177/000486588802100 405.

Morris, A. S., Silk, J., Steinberg, L., Sessa, F. M., Avenevoli, S., \& Essex, M. J. (2002). Temperamental vulnerability and negative parenting as interacting predictors of child adjustment. Journal of Marriage and Family, 64, 461-471. https://doi.org/10.1111/j.1741-3737.2002.00461.x.

Muris, P., \& Meesters, C. (2009). Reactive and regulative temperament in youths: Psychometric evaluation of the early adolescent temperament questionnaire-revised. Journal of Psychopathology and Behavioral Assessment, 31, 7-19. https://doi.org/10.1007/s10862-008-9089-x.

Muris, P., Merckelbach, H., Schmidt, H. G., \& Mayer, B. (1999). The revised version of the Screen for Child Anxiety Related Emotional Disorders (SCARED-R): Factor structure in normal children. Personality and Individual Differences, 26, 99-112. https://doi.org/10.1016/s0191-8869(98)00130-5.

Muris, P., Merckelbach, H., Van Brakel, A., Mayer, B., \& Van Dongen, L. (1998). The Screen for Child Anxiety Related Emotional Disorders (SCARED): Relationship with anxiety and depression in normal children. Personality and Individual Differences, 24, 451-456. https://doi.org/10.1016/s0191 -8869(97)00217-1.

Oldehinkel, A. J., Hartman, C. A., De Winter, A. F., Veenstra, R., \& Ormel, J. (2004). Temperament profiles associated with internalizing and externalizing problems in preadolescence. Development and Psychopathology, 16, 421-440. https://doi.org/10.1017/s0954579404044591.

Pavlova, M. K., Haase, C. M., \& Silbereisen, R. K. (2011). Early, on-time, and late behavioral autonomy in adolescence: Psychosocial correlates in young and middle adulthood. Journal of Adolescence, 34, 361-370. https://doi.org/10.1016/j.adolescence.2010.04.002.

Pérez-Edgar, K. (2015). Effortful control in adolescence: Individual differences within a unique developmental window. In G. Oettingen \& P. M. Gollwitzer (Eds.), Self-Regulation in Adolescence. Cambridge: Cambridge University Press.

Pettit, G. S., Laird, R. D., Dodge, K. A., Bates, J. E., \& Criss, M. M. (2001). Antecedents and behaviorproblem outcomes of parental monitoring and psychological control in early adolescence. Child Development, 72, 583-598. https://doi.org/10.1111/1467-8624.00298.

Poulin, C., Hand, D., \& Boudreau, B. (2005). Validity of a 12-item version of the CES-D used in the National Longitudinal Study of Children and Youth. Chronic Diseases in Canada, 26, 65-72.

Radloff, L. S. (1977). The CES-D Scale: A self-report depression scale for research in the general population. Applied Psychological Measurement, 1, 385-401. https://doi.org/10.1177/014662167700100306.

Reitz, E., Dekovic, M., \& Meijer, A. M. (2006). Relations between parenting and externalizing and internalizing problem behavior in early adolescence: Child behavior ad moderator and predictor. Journal of Adolescence, 29, 419-436. https://doi.org/10.1016/j.adolescence.2005.08.003.

Rothbart, M. K. (1989). Temperament and development. In G. A. Kohnstamm, J. A. Bates, \& M. K. Rothbart (Eds.), Temperament in childhood (pp. 187-247). New York: Wiley. 
Russel, C. J., \& Dean, M. A. (2000). To log or not to log: Bootstrap as an alternative to the parametric estimation of moderation effect in the presence of skewed dependent variables. Organizational Research Methods, 3, 166-185. https://doi.org/10.1177/109442810032002.

Rutter, M. (2001). Psychosocial adversity: Risk, resilience, and recovery. In J. M. Richman \& M. W. Fraser (Eds.), The context of youth violence: Resilience, risk, and protection (pp. 13-41). Westport, CT: Praeger.

Sentse, M., Dijkstra, J. K., Lindenberg, S., Ormel, J., \& Veenstra, R. (2010). The delicate balance between parental protection, unsupervised wandering, and adolescents' autonomy and its relation with antisocial behavior. International Journal of Behavioral Development, 34, 159-167. https://doi. org/10.1177/0165025409350949.

Soenens, B., Beyers, W., Vansteenkiste, M., Sierens, E., Luyckx, K., \& Goossens, L. (2004, July). The "gross anatomy" of parenting styles in adolescence: Three or four dimensions? In: Paper presented at the 18th biennial meeting of the International Society for the Study of Behavioral Development (ISSBD), Ghent, Belgium.

Soenens, B., \& Vansteenkiste, M. (2005). Antecedents and outcomes of self-determination in 3 life domains: The roles of parents' and teachers' autonomy support. Journal of Youth and Adolescence, 34, 589-604. https://doi.org/10.1007/s10964-005-8948-y.

Soenens, B., Vansteenkiste, M., Lens, W., Luyckx, K., Goossens, L., Beyers, W., et al. (2007). Conceptualizing parental autonomy support: Adolescent perceptions of promotion of independence versus promotion of volitional functioning. Developmental Psychology, 43, 633. https://doi. org/10.1037/0012-1649.43.3.633.

Steinberg, L. (1987). Impact of puberty on family relations: effects of pubertal status and pubertal timing. Developmental Psychology, 23, 451. https://doi.org/10.1037/0012-1649.23.3.451.

Steinberg, L. (2001). We know some things: Parent-adolescent relationships in retrospect and prospect. Journal of Research on Adolescence, 11, 1-19. https://doi.org/10.1111/1532-7795.0000.

Steinberg, L., \& Morris, A. S. (2001). Adolescent development. Annual Review of Psychology, 52, 83-110. https://doi.org/10.1891/194589501787383444.

Steinberg, L., \& Silk, J. S. (2002). Parenting adolescents. In M. H. Bornstein (Ed.), Handbook of parenting volume 1: children and parenting (pp. 103-133). New Jersey: Lawrence Erlbaum Associates.

Stice, E., \& Gonzales, N. (1998). Adolescent temperament moderates the relation of parenting to antisocial behavior and substance use. Journal of Adolescent Research, 13, 5-31. https://doi.org/10.1177/07435 54898131002.

Tanner, J. M., Whitehouse, R. H., \& Takaishi, M. (1966). Standards from birth to maturity for height, weight, height velocity, and weight velocity: British children, 1965. Archives of Disease in Childhood, 41, 455-471.

Valiente, C., Lemery-Chalfant, K., Swanson, J., \& Reiser, M. (2008). Prediction of children's academic competence from their effortful control, relationships, and classroom participation. Journal of Educational Psychology, 100, 67. https://doi.org/10.1037/0022-0663.100.1.67.

Van der Laan, A., Veenstra, R., Bogaerts, S., Verhulst, F. C., \& Ormel, J. (2010). Serious, minor, and non-delinquents in early adolescence: The impact of cumulative risk and promotive factors. The TRAILS study. Journal of Abnormal Child Psychology, 38, 339-351. https://doi.org/10.1007/s1080 2-009-9368-3.

Van Leeuwen, K. G., Mervielde, I., Braet, C., \& Bosmans, G. (2004). Child personality and parental behavior as moderators of problem behavior: Variable- and person-centered approaches. Developmental Psychology, 40, 1028. https://doi.org/10.1037/0012-1649.40.6.1028.

Van Petegem, S., Vansteenkiste, M., \& Beyers, W. (2013). The jingle-jangle fallacy in adolescent autonomy in the family: In search of an underlying structure. Journal of Youth and Adolescence, 42(7), 9941014. https://doi.org/10.1007/s10964-012-9847-7.

Veenstra, R., Lindenberg, S., Oldehinkel, A., De Winter, A. F., \& Ormel, J. (2006). Temperament, environment, and antisocial behavior in a population sample of preadolescent boys and girls. International Journal of Behavioral Development, 30, 422-432. https://doi.org/10.1177/0165025406071490. 


\section{Affiliations}

\section{J. A. B. M. Houtepen ${ }^{1,2} \mathbb{D} \cdot$ J. J. Sijtsema ${ }^{1,2} \mathbb{D} \cdot$ T. A. Klimstra ${ }^{1} \cdot$ R. Van der Lem ${ }^{2} \mathbb{D}$. S. Bogaerts ${ }^{1,2}$ (D)}

1 Department of Developmental Psychology, Tilburg University, Professor Cobbenhagenlaan 225, 5037 DB Tilburg, The Netherlands

2 Fivoor Research and Treatment Innovation, Forensic Outpatient Center Rotterdam, Diergaardesingel 69-73, 3014 AE Rotterdam, The Netherlands 